\title{
Immunomodulatory Role of Mesenchymal Stem Cells against Multiple Sclerosis
}

\author{
Amir Ghaemi ${ }^{1,2}$, Shahnaz Babaei Abraki², Sedigheh Ghasemi², Azadeh Sajadian², Mansoureh Togha ${ }^{3 *}$ \\ ${ }^{1}$ Infectious Diseases Research Center, Department of Microbiology, Golestan University of Medical Sciences, Gorgan, Iran. \\ ${ }^{2}$ Shefa Neuroscience Research Center, Khatam Alanbia Hospital, Tehran, Iran. \\ ${ }^{3}$ Iranian Center of Neurological Research, Neuroscience Research Institute, Tehran University of Medical Sciences, Tehran, Iran.
}

\section{A BSTRACT}

Introduction: Multiple sclerosis (MS) is an autoimmune disease of central nervous system that is characterized by the progressive loss of myelin. In addition to immunoregulatory properties, novel MS therapies promote myelin repair activities. Mesenchymal stem cells (MSCs) have been viewed as a potent tool for regenerative and immunosuppressive functions, indicating a potential therapy for MS. MSCs have immunological functions which are exerted by direct cell-to-cell contacts, secretion of stimulatory and inhibitory cytokines, and/or a combination of both mechanisms. Therefore, these cells can inhibit differentiation and proliferation of T-cell and stimulate the Th2 and regulatory T-cells through inhibitory effects on the immune system. Conclusion: In the current review, we discuss the mechanisms underlying the immunomodulatory effect of MSCs in different experimental models of MS.

\section{Key words:}

1. Cell- and TissueBased Therapy 2. Immunomodulation 3. Multiple Sclerosis

4. Mesenchymal Stromal Cells

* Corresponding Author: Mansoureh Togha

E-mail: toghae@tums.ac.ir 


\title{
نقش تنظيم ايمنى سلولهاى بنيادى مزانشيمى در مالتييل اسكلروز
}

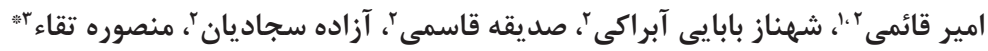 \\ مركز تحقيقات بيمارىهاى عفونى، كروه ميكروب شناسى، دانشكاه علوم يزشكى كلستان، كرَّان، ايران.

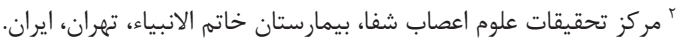

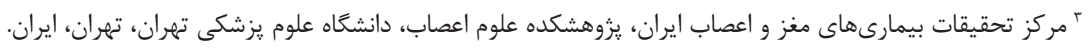

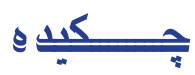

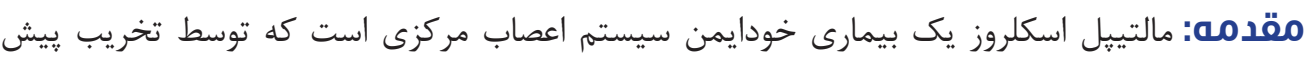

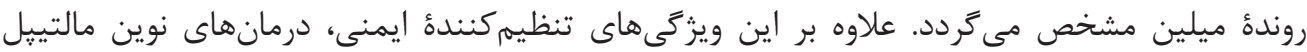

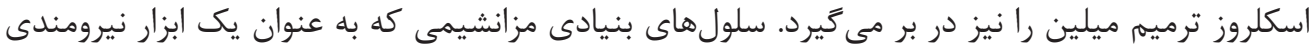

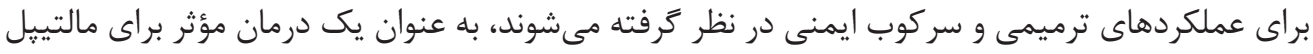

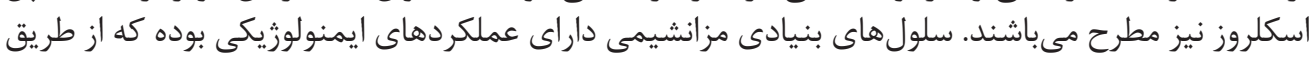

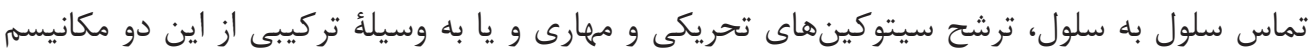

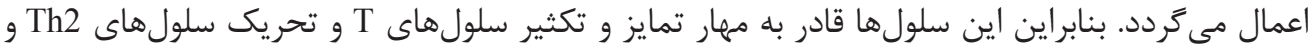

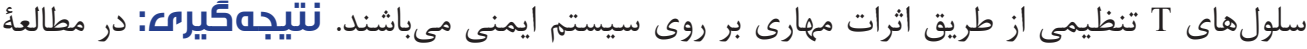

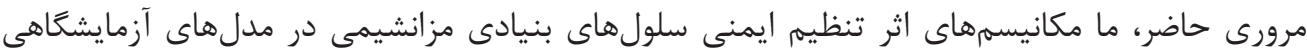
مختلف مالتيبل اسكلروز را مورد بررسى قرار دانيم تنظيم ايمني

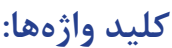

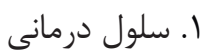

r.

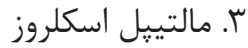
بأ. سلولهاى استرومايى السكروز مزانشيمى 
عود -خاموشى مفيد باشند، اما با اين وجود اين داروها اغلب

داراى عوارض جانبى متعدد هستند (9 ، ه).

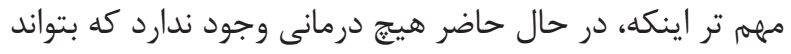

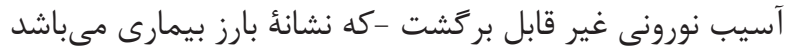

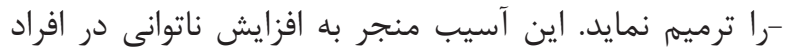

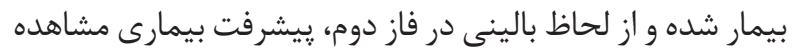

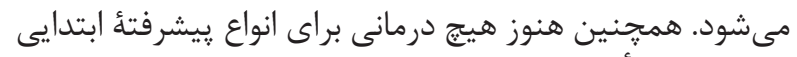

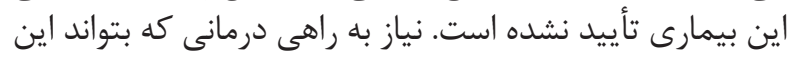

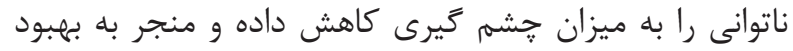

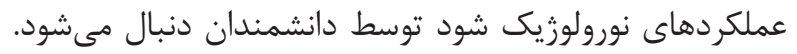

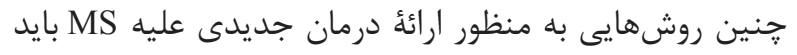

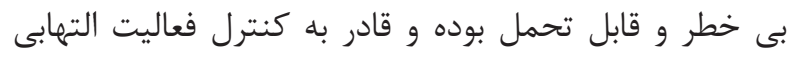

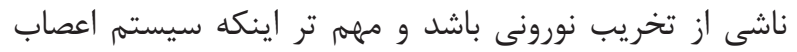

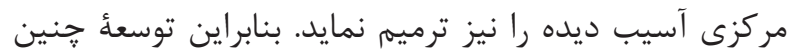

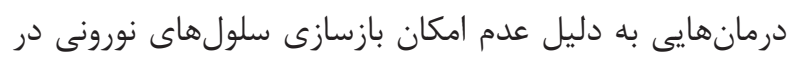

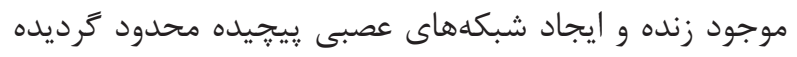

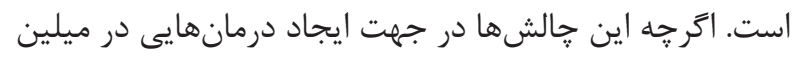

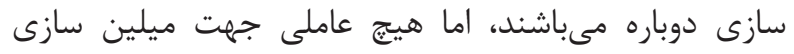

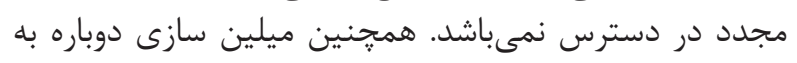

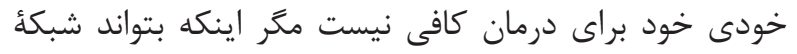

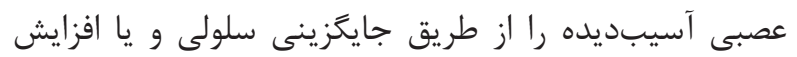

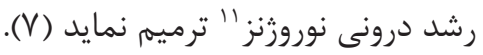

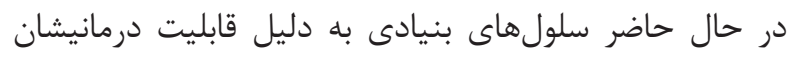

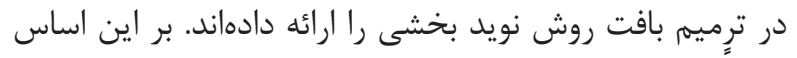

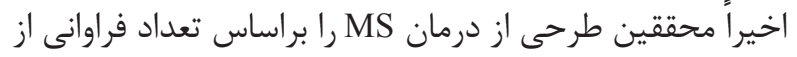

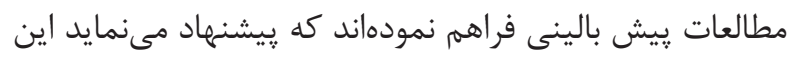

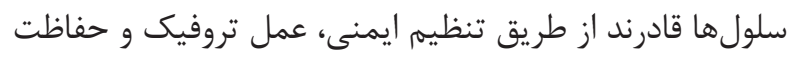

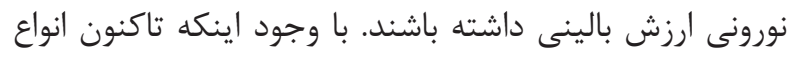

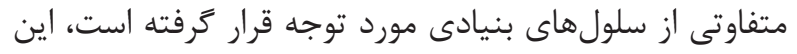

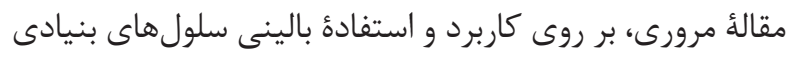

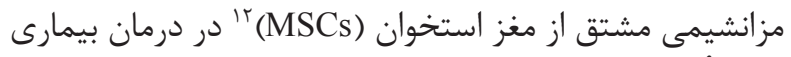

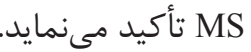

ا- انواع سلول هاى مورد توجه براى درمان بيمارى MS

$$
\text { 1-1- إلولهاى بنيادى جنينى }
$$

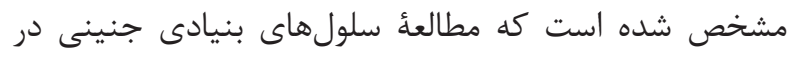

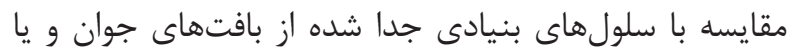

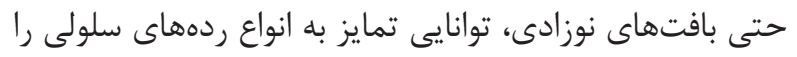

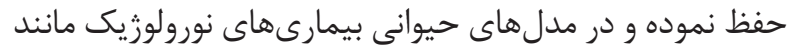

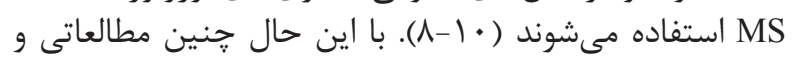

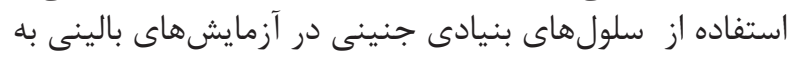
دليل موارد اخلاقى و مسائل قانونى با محدوديتهائى دازئ مواجه شده است.

\footnotetext{
${ }^{1}$ Multiple sclerosis (MS)

${ }^{2}$ Central nervous system (CNS)

${ }^{3}$ Relapsing-Remitting (RR)

${ }^{4}$ Experimental autoimmune encephalomyelitis (EAE)

${ }^{5}$ Chronic-relapsing

${ }^{6}$ Reactive oxygen species (ROS)
}

بيمارى اسكلروز منتشر (MS)' يكى بيمارى خود ايمن محسوب

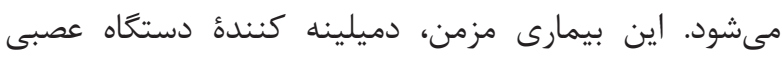

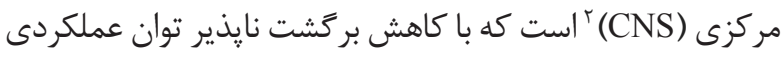

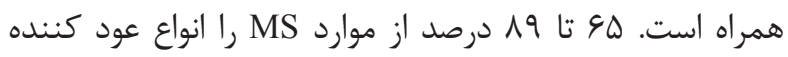

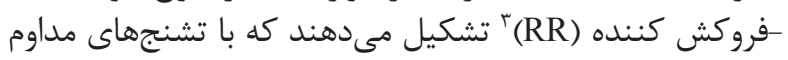

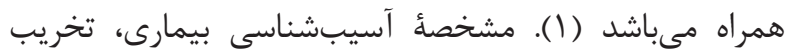

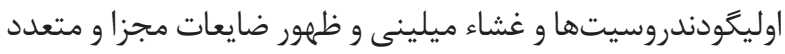

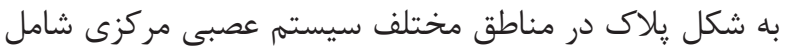

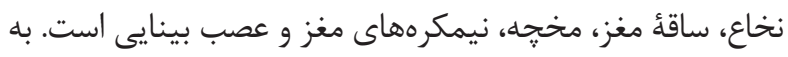

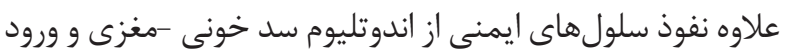

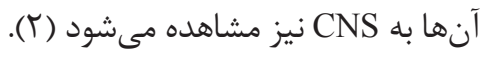

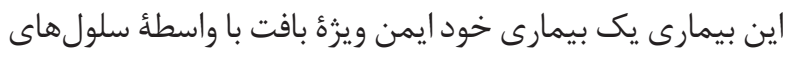

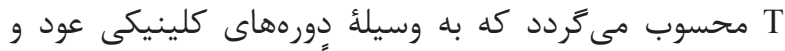

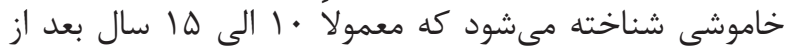

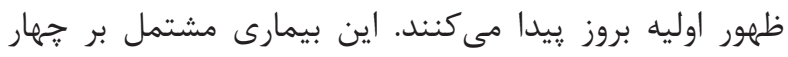

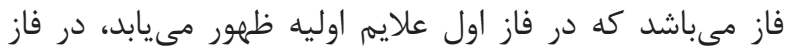

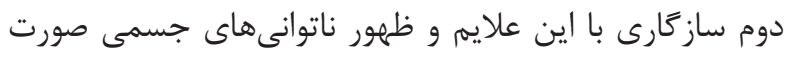

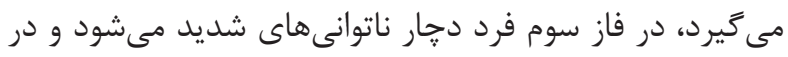

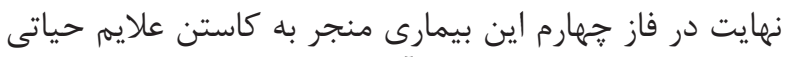

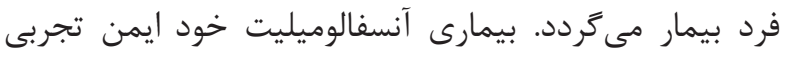

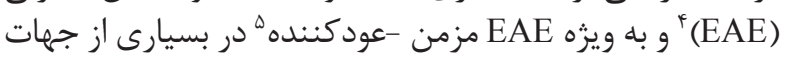

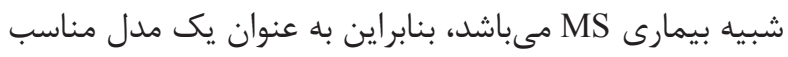

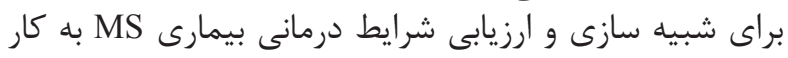

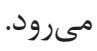

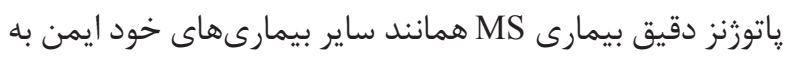

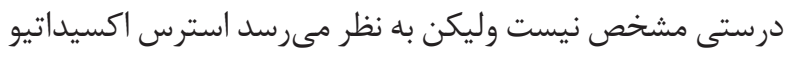

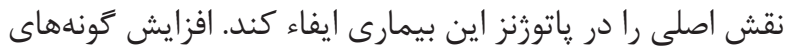

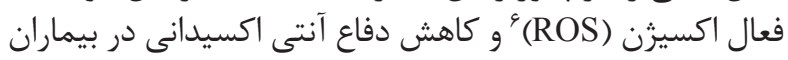

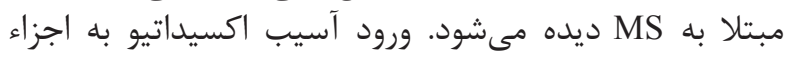

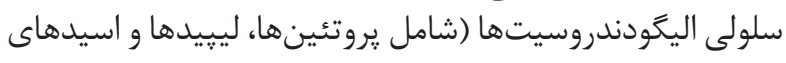

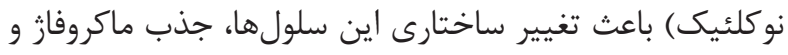

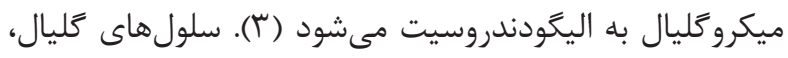

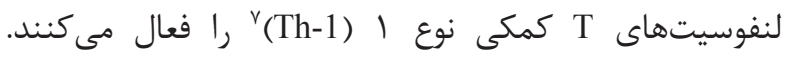

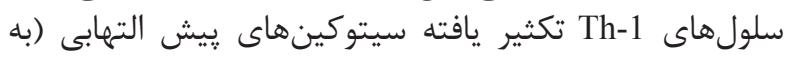
ويزه فاكتور نكروزى -تومورى آلفا (TNF-

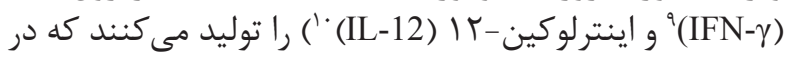

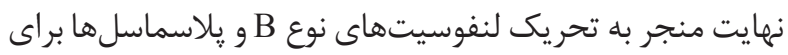

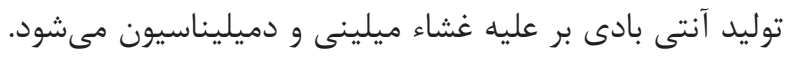

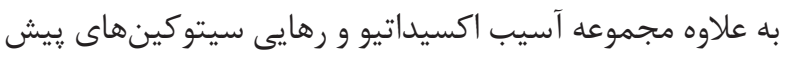

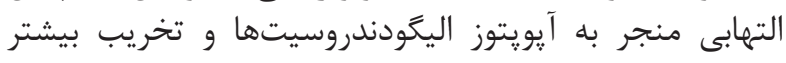

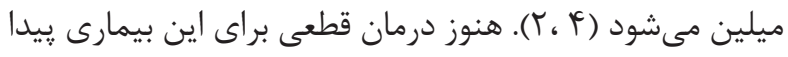

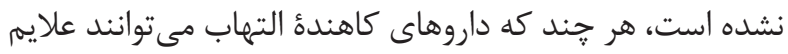

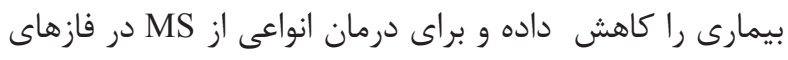

${ }^{7} \mathrm{~T}$ helper 1 (Th-1)

${ }^{8}$ Tumor necrosis factor $\alpha(\mathrm{TNF} \alpha)$

${ }^{9}$ Interferon $\gamma($ IFN $\gamma)$

${ }^{10}$ Interleukin-12 (IL-12)

${ }^{11}$ Neurogenesis

${ }^{12}$ Mesenchymal stem cells (MSCs) 
اشاره نمود. به نظر مىرسد MSC ها داراى ويزّكى هايى

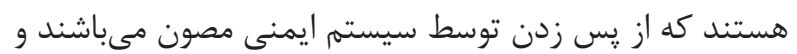

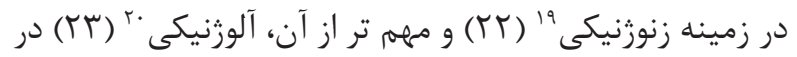

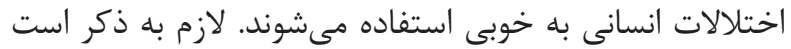
كه در برخى مطالعات نيز مشاهده شده است است كه إنه

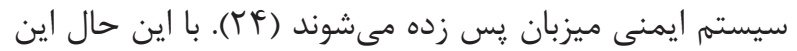

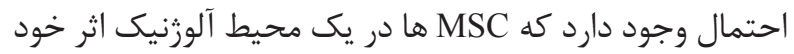

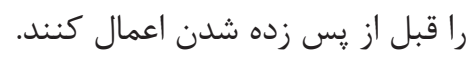

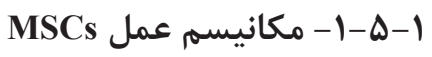

علاوه بر نقش فيزيولوزيك MSC ها در مغزاستخوان، MSC ها

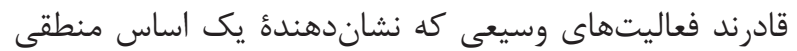

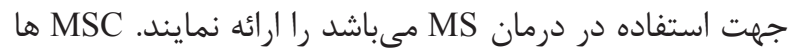

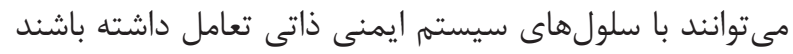

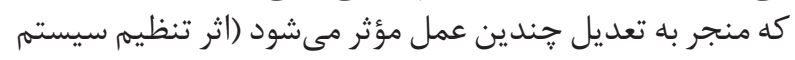

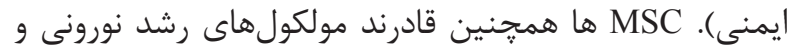

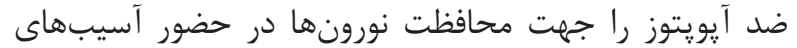
عصبى آزاد كنند (اثر حفاظت نورونتي).

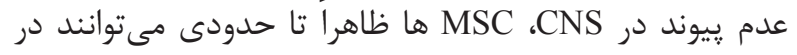

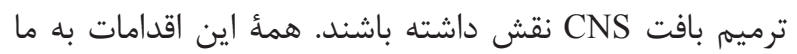
در تعريف اصطلاح "انعطاف درمانى " MSC ها كمكى مي كنئند

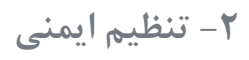

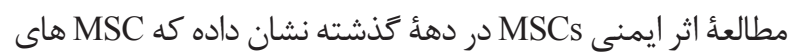

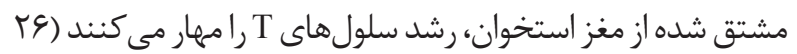

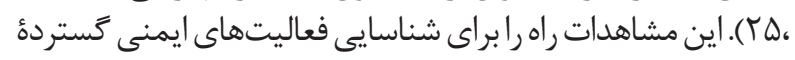

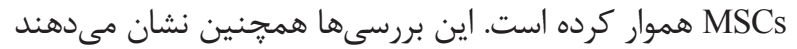

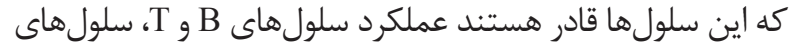

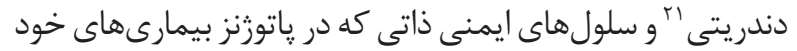

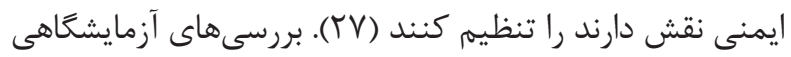

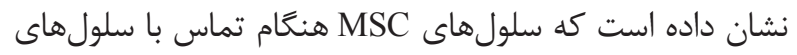

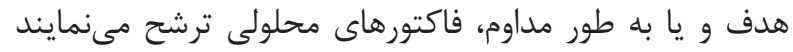

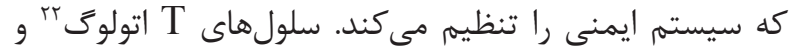

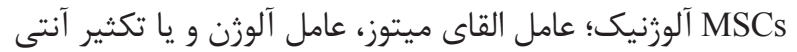

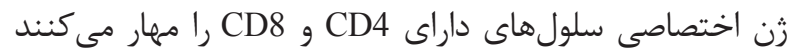

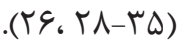

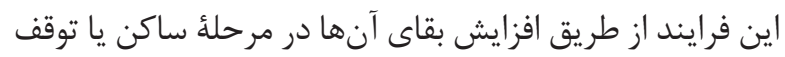

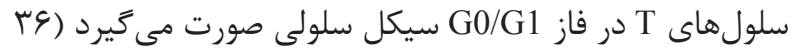

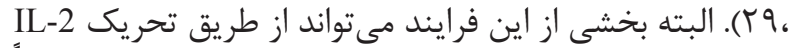

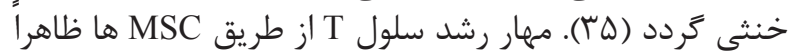

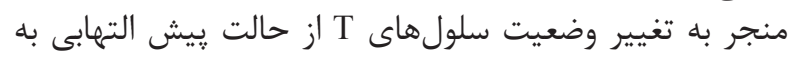

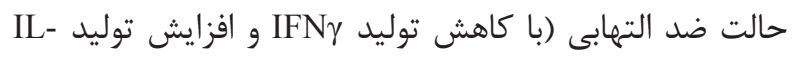

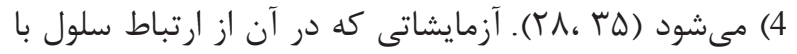

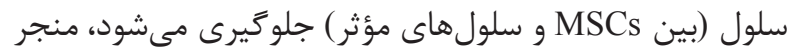

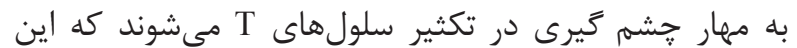

\footnotetext{
${ }^{13}$ Neural precursor cells (NPCs)

${ }^{14}$ Progenitor

${ }^{15}$ Major histocompatibility complex (MHC)

${ }^{16}$ Induced pluripotent stem cells (iPSCs)

${ }^{17}$ Hematopoietic stem cells (HSC)
}

\section{1-Y- سلولهاى بيش ساز عصبى (NPCs)}

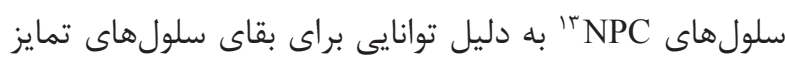

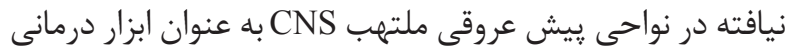

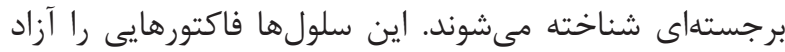

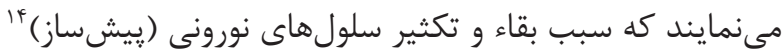

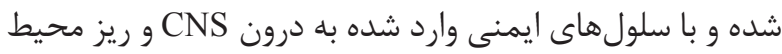

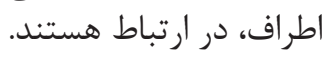

تزريق درون وريدى يا درون نخاعى NPC ها در موش اثر

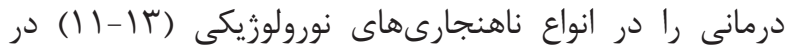

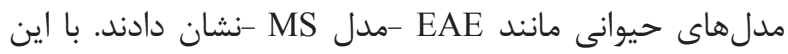

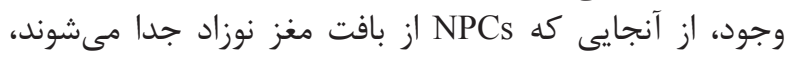

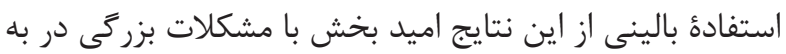

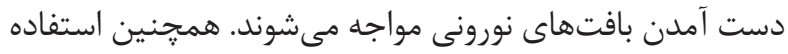

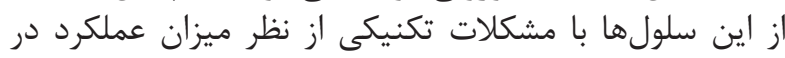

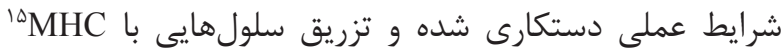

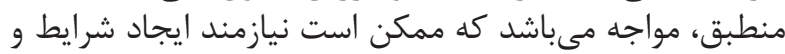

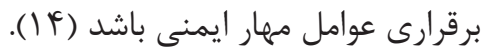

\section{1-r- سلولهاى بنيادى ير توان القايى (iPSCs)}

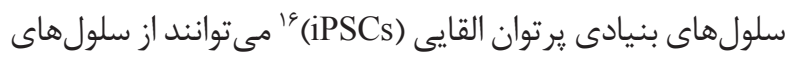

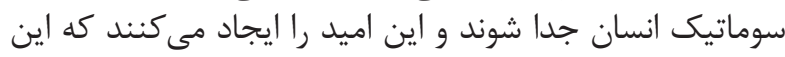

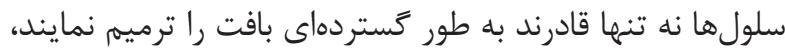

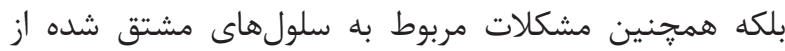

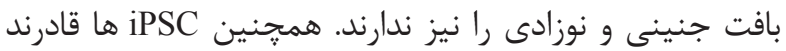

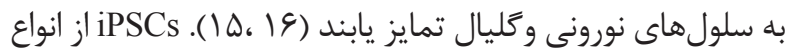

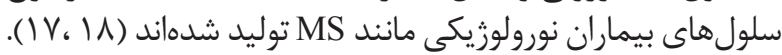

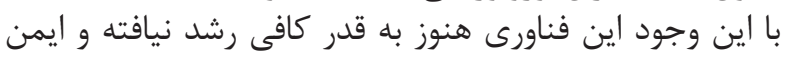

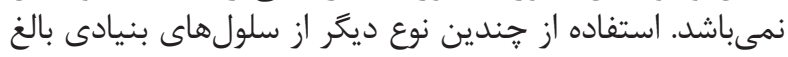
نيز بررسى شده است.

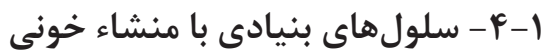

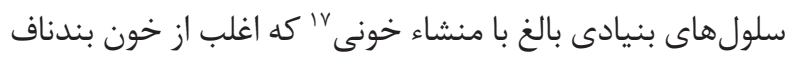

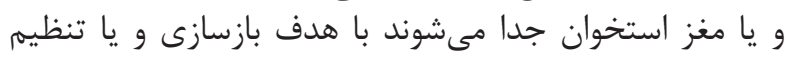

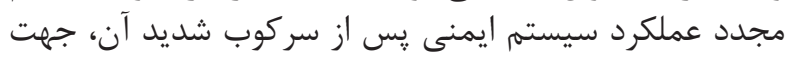

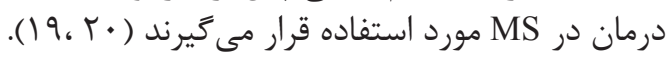

\section{1-هله - سلول هاى بنيادى مزانشيمى (MSCs)}

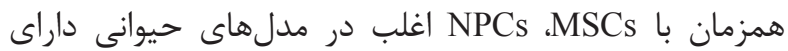

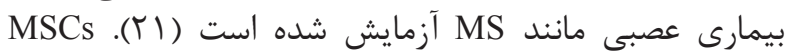

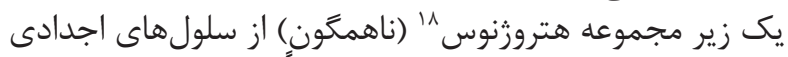

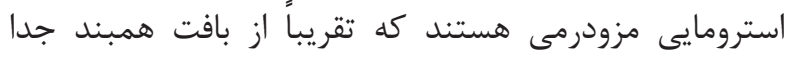

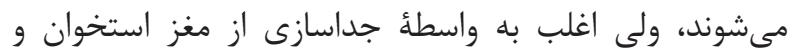

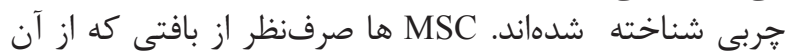

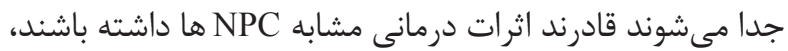

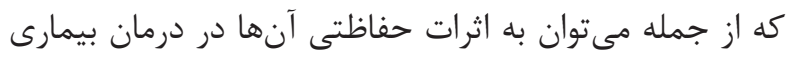

\footnotetext{
${ }^{18}$ Heterogeneous

${ }^{19}$ Xenogeneic

${ }^{20}$ Allogeneic

${ }^{21}$ Dendritic cells (DC)

${ }^{22}$ Autologous
} 


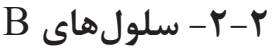

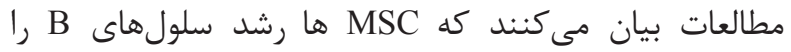

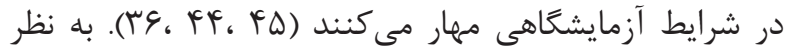

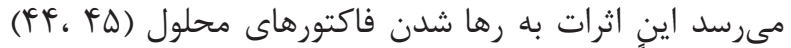

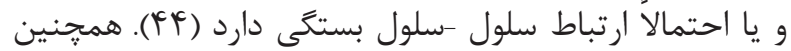

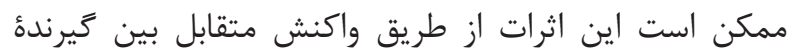

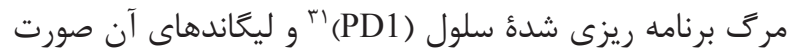

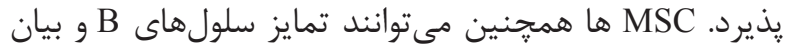

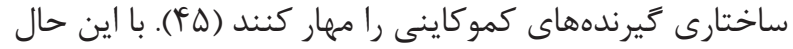

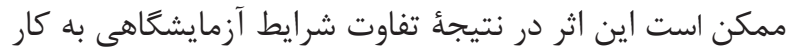

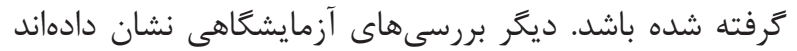

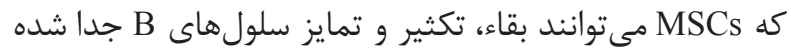

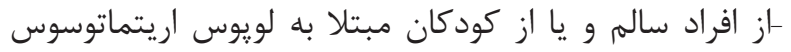

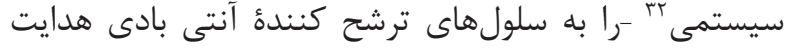

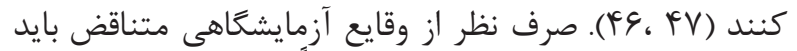

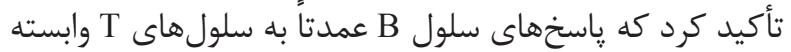

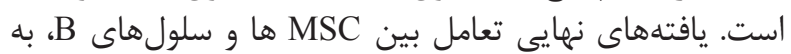

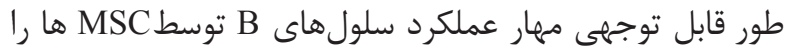
نشان مى ندهند.

\section{r-r- - سلول هاى دندريتى}

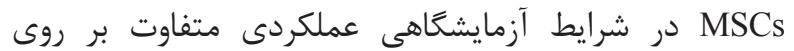

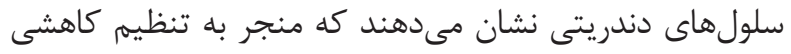

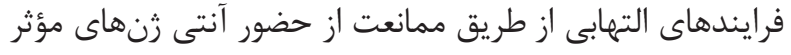

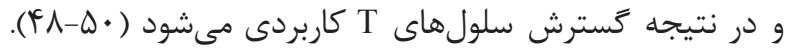

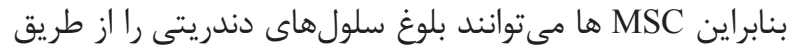

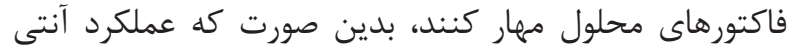

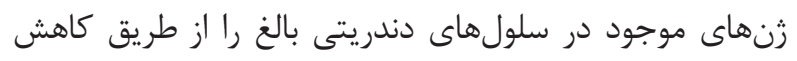

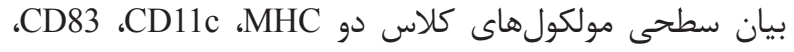

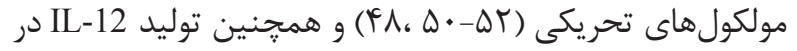

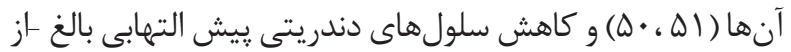

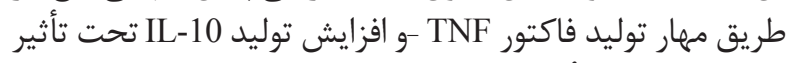

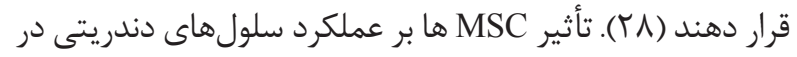

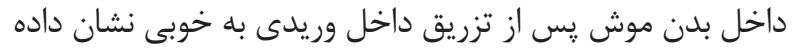

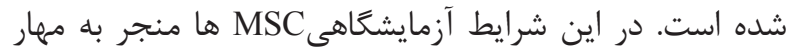

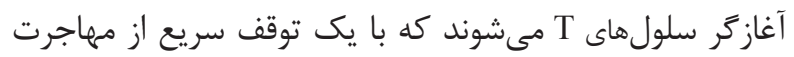

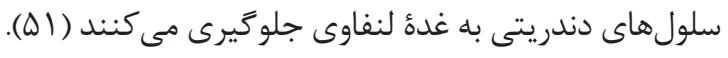

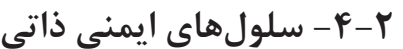

هSC ها همجنين مى توانند بر سلول هاى سيستم ايمنى ذاتى

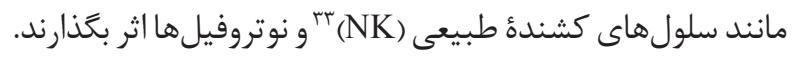

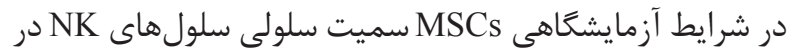
حال استراحت را از طريق جلوَيرى از بيان كيرندههاى فعال

${ }^{23}$ Transforming growth factor- $\beta 1$ (TGF- $\beta 1$ )

${ }^{24}$ Hepatocyte growth factor (HGF)

${ }^{25}$ Human leukocyte antigen class 1 (HLA-G1)

${ }^{26}$ Indoleamine 2,3-dioxygenase (IDO)

${ }^{27}$ Fail-safe mechanisms

${ }^{28}$ Toll-like receptors (TLR)
مهار نقش فاكتورهاى محلول را در اين فرايند نشان مىدهدي.

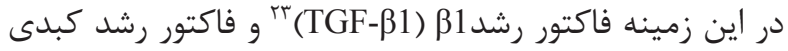

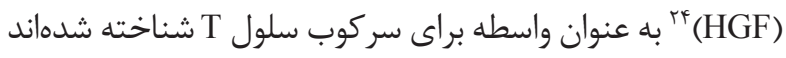

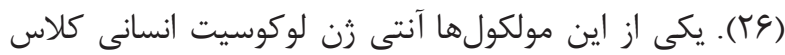
(HLA-G1) 1

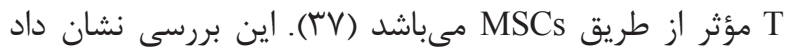

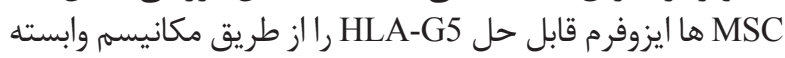

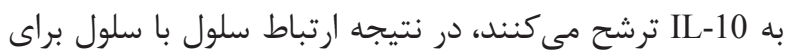

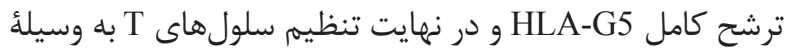

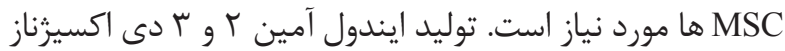

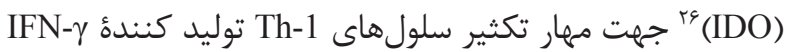

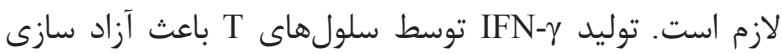

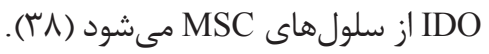

T-ا- سلولهاى T تنظيمى

ها از دو روش مستقيم و غيرمستقيم بر روى سلولهاى

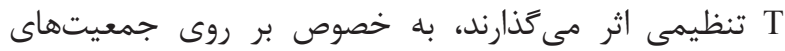

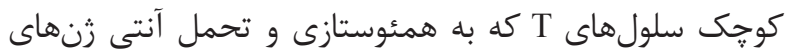

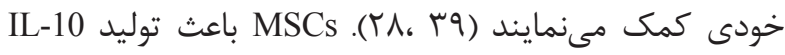

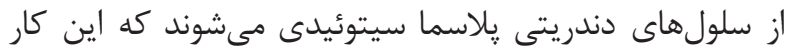

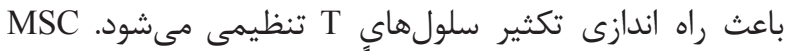

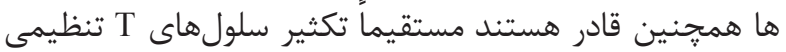

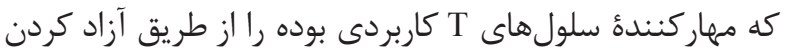
دLA-G5

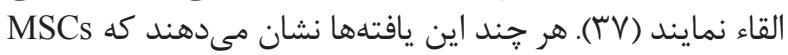

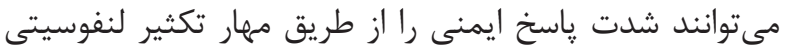

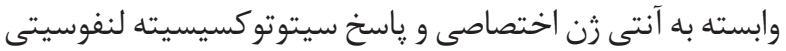

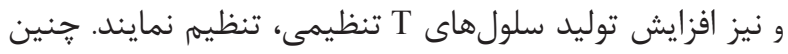

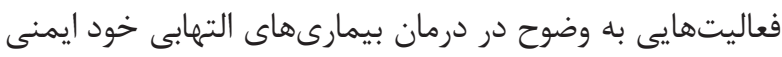

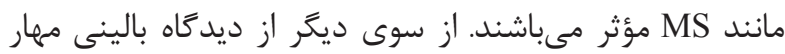

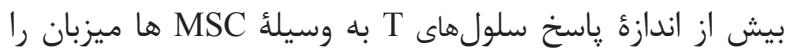

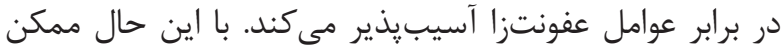

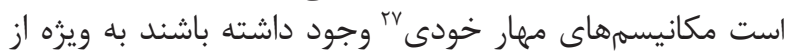

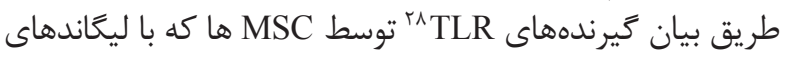

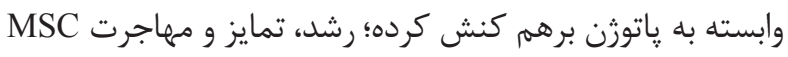

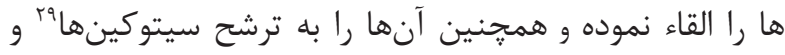

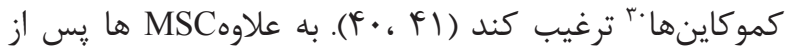

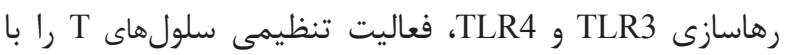

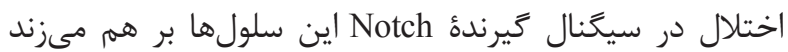

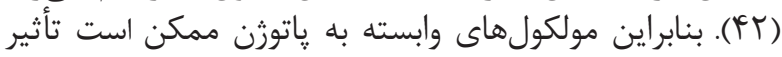

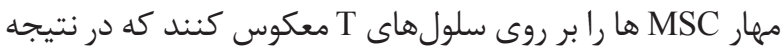

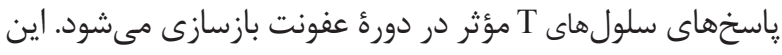

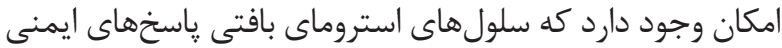

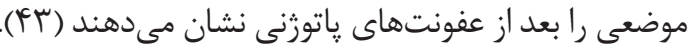

\footnotetext{
${ }^{29}$ Cytokine

${ }^{30}$ Chemokine

${ }^{31}$ Programmed cell death1 (PD1)

${ }^{32}$ Systemic lupus erythematosus (SLE)

${ }^{33}$ Natural killer (NK)
} 


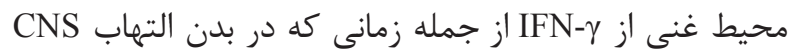

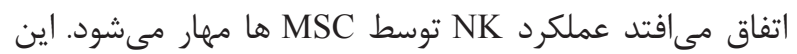

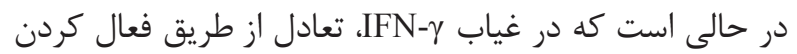

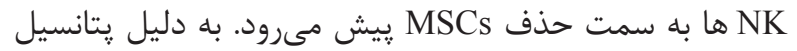

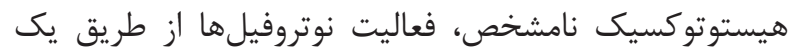

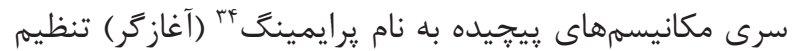

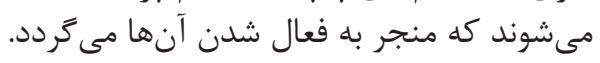
شواهدى از برايمينَ نوتروفيلها در بيمارىهاى خود ايمنى

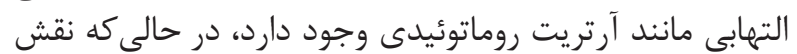

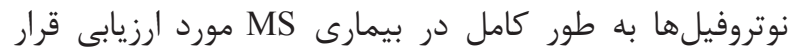

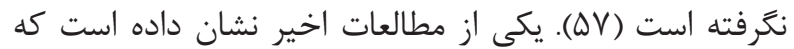

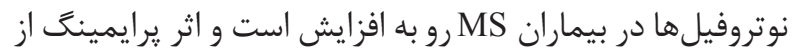

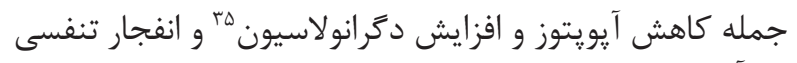

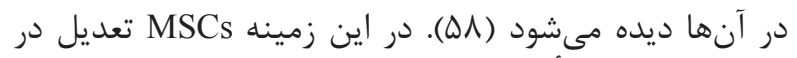

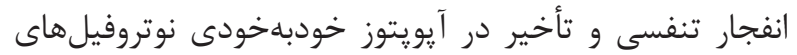

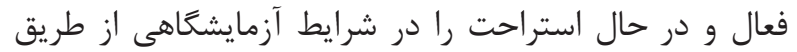

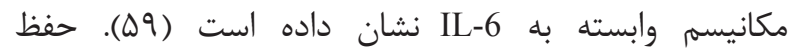

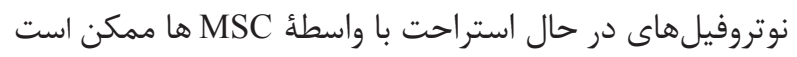

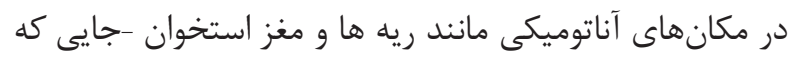

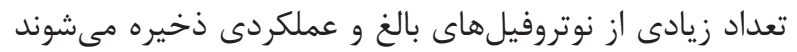

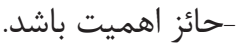

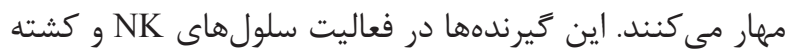

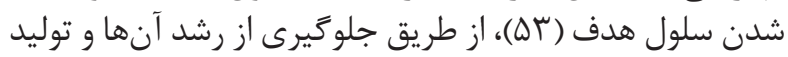

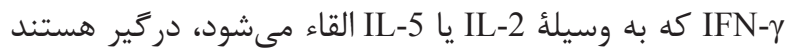

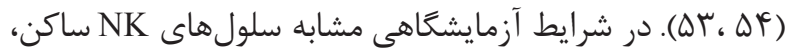

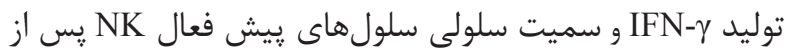

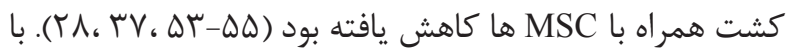

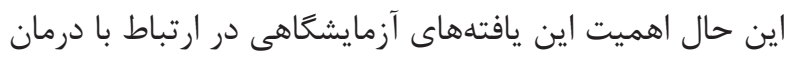

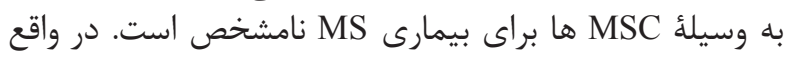

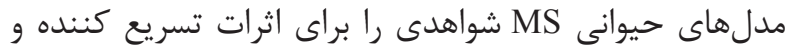

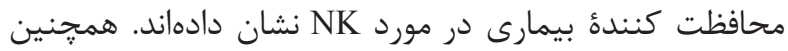

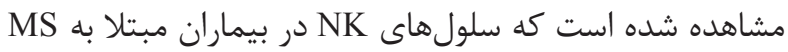

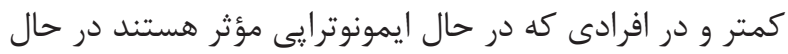

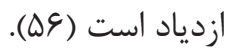

احرجه اين مشاهدات نشان مى دهند كه اين لنفوسيتهاى ذاتى

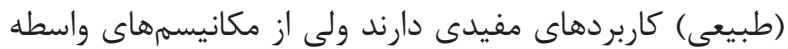
مانند تنظيم ايمنى سلولهي هاى NK دردي مفيدى دارني

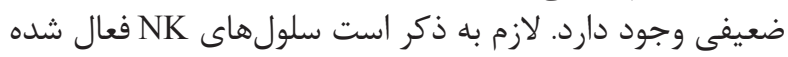

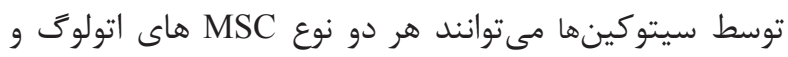

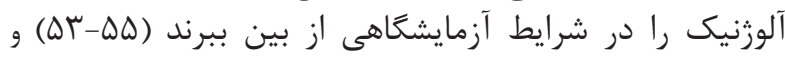

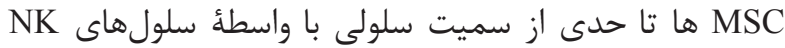

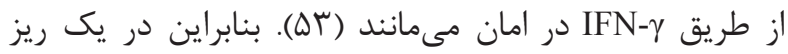

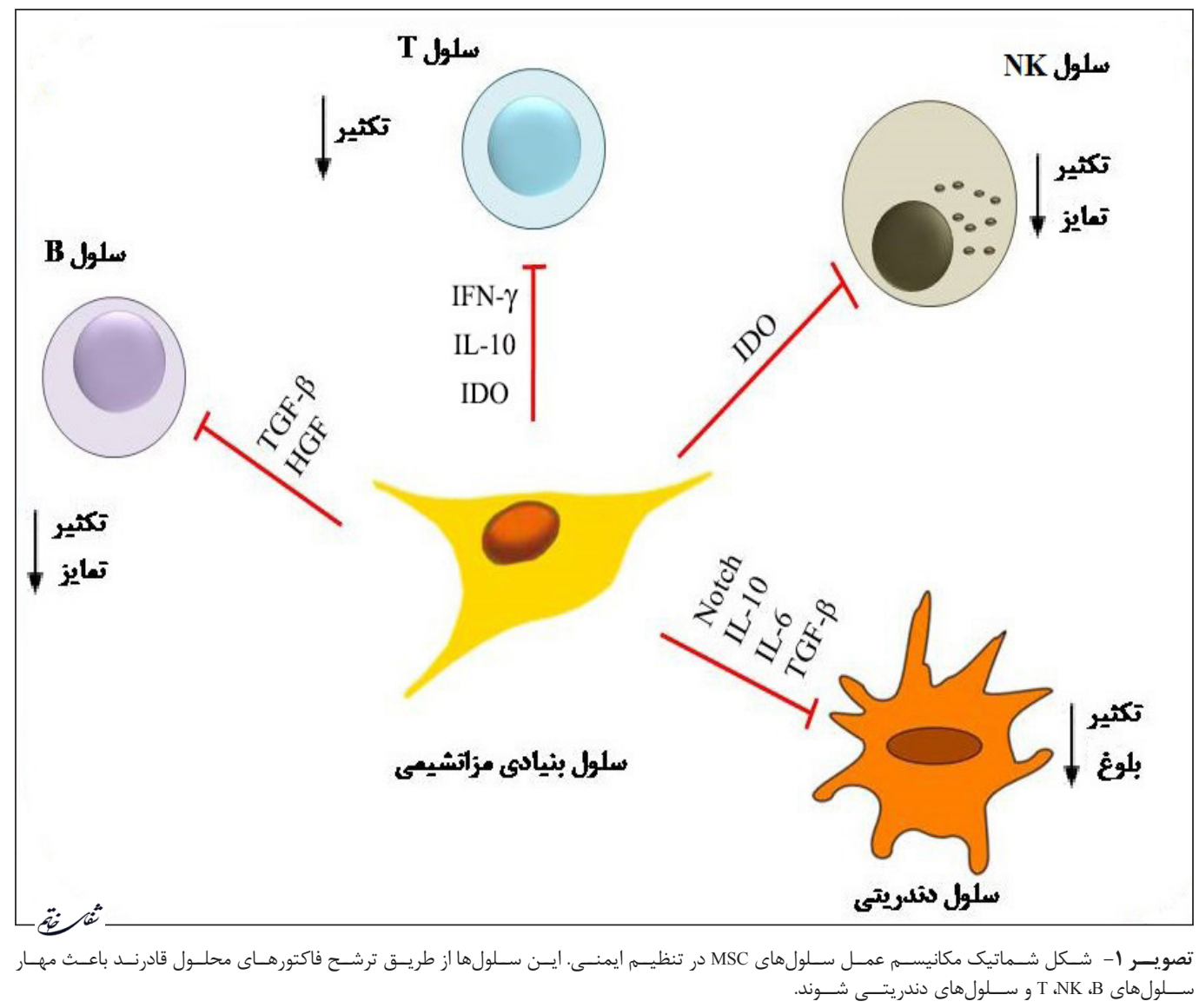

${ }^{34}$ Priming

${ }^{35}$ Degranulation 


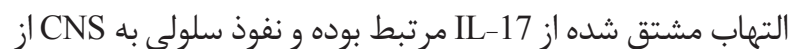

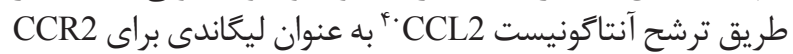

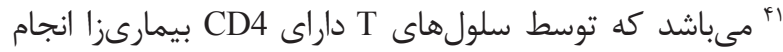

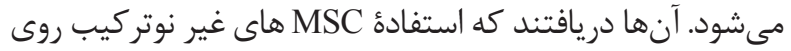

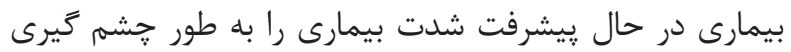

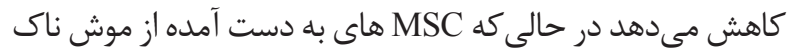

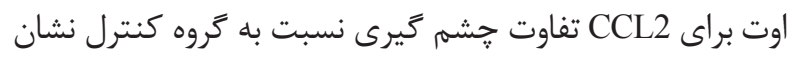

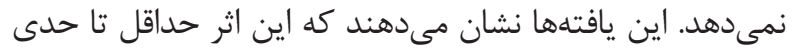

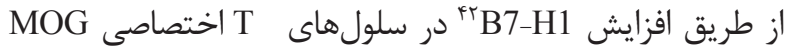

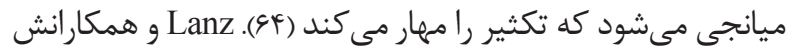

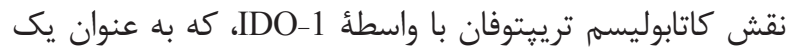

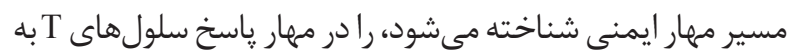

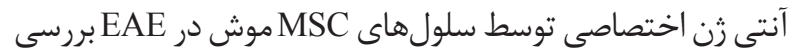

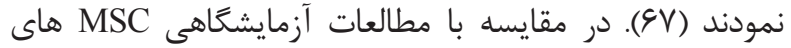

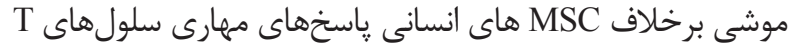

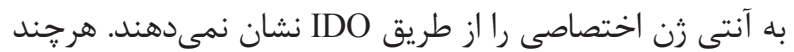

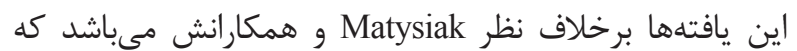

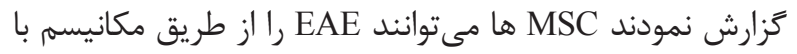

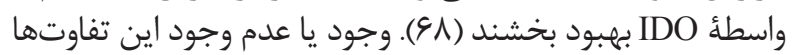

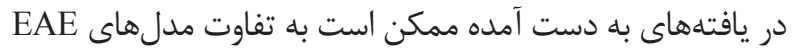

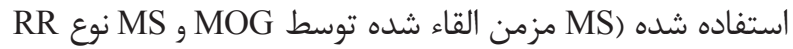
القاء شده توسط PLP) مرتبط باشد.

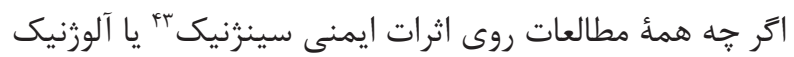

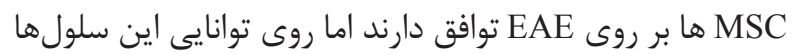

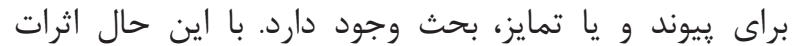

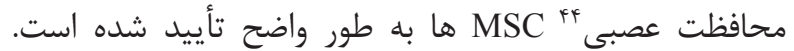

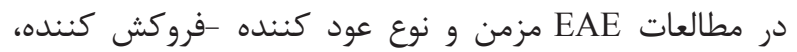

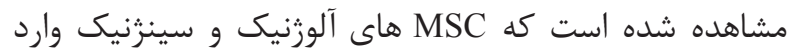

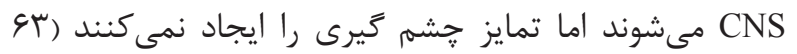

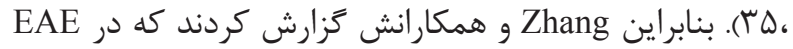
القاء شده توسط PLP، به بن كارگيرى

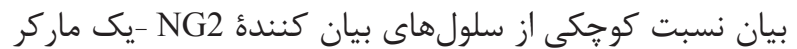

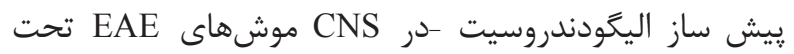

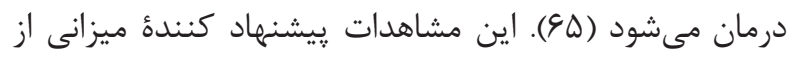

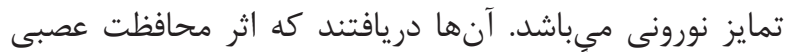

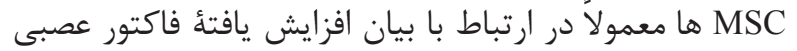

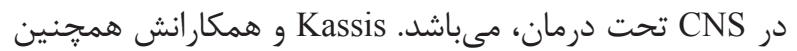

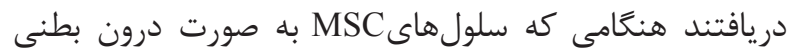

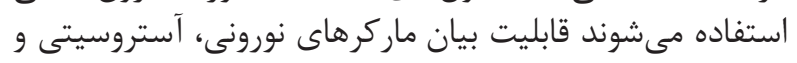

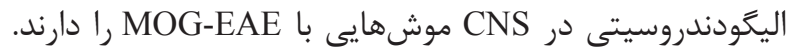

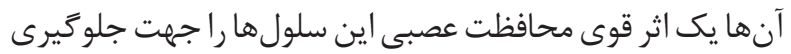

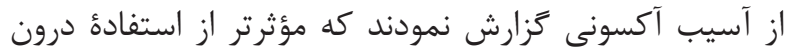

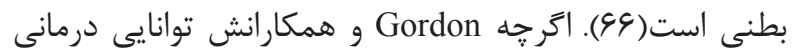

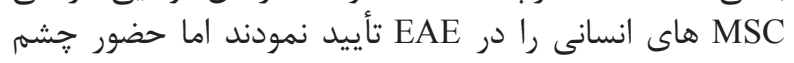

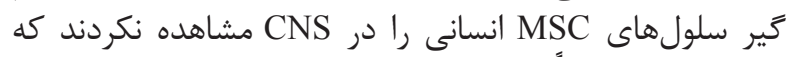

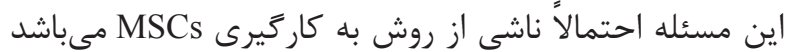

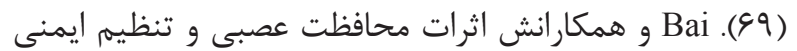

${ }^{36}$ Paracrine mechanisms

${ }^{37}$ Myelin oligodendrocyte glycoprotein (MOG)

${ }^{38}$ Proteolipid protein (PLP)

${ }^{39}$ Green fluorescent protein-Mesenchymal stem cell

${ }^{40}$ Chemokine (C-C motif) ligand 2 (CCL2)
نتيجه گَيرى

مطالعات روى مدل EAE و همجنين ديخر مدل تهاى بيمارى هاى

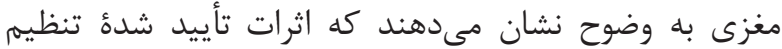

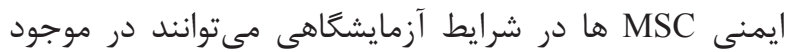

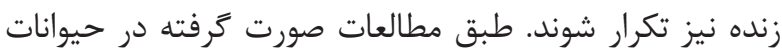

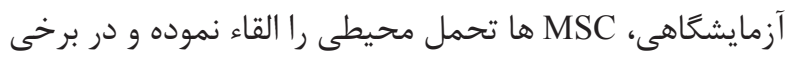

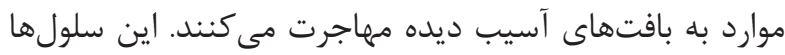

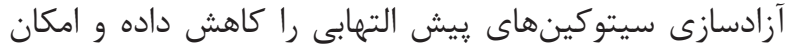

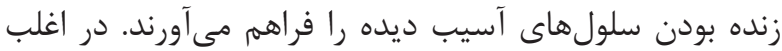

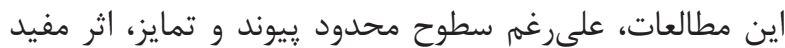

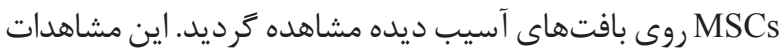

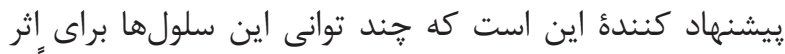

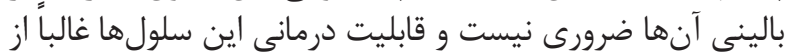

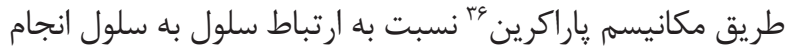

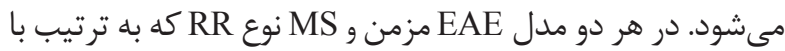

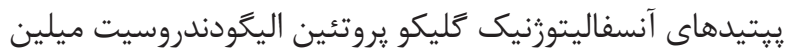
ها و يروتئين بروتئوليييد (MOG35-55)

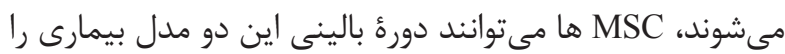

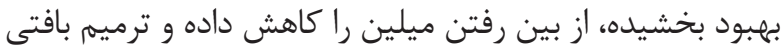

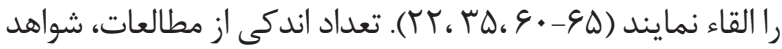

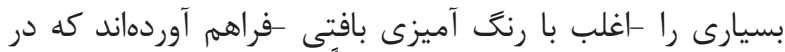

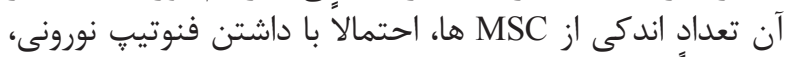
مستقيماً در CNS وارد شدهاند (199، (94).

در اولين مطالعه با كارَيرى MSC ها در مدل EAE (تزريق

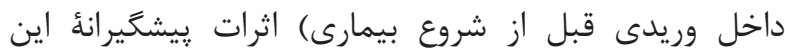

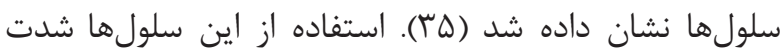

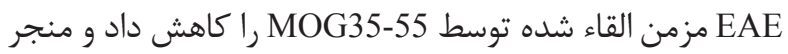

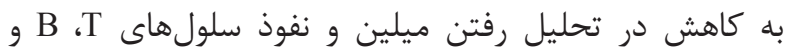

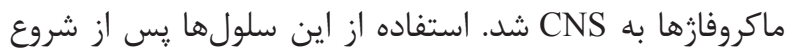

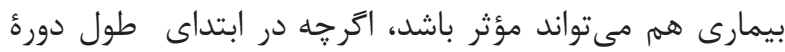

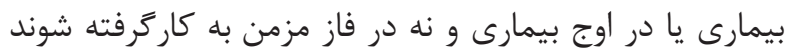

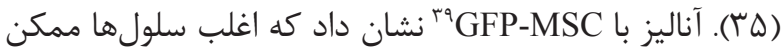

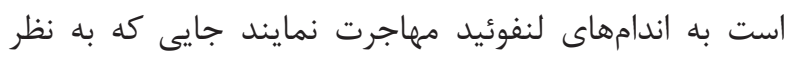

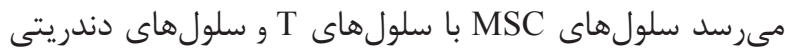

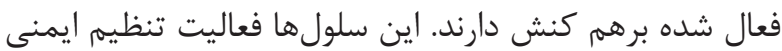

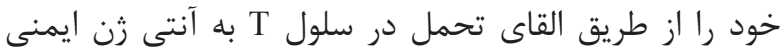

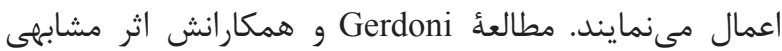

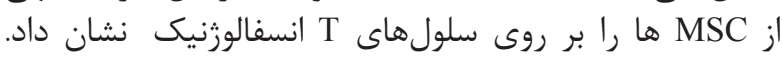

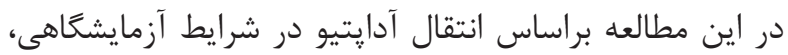

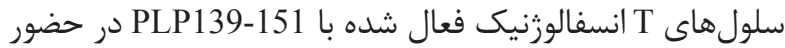

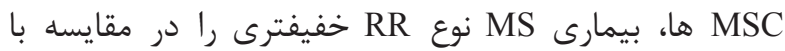

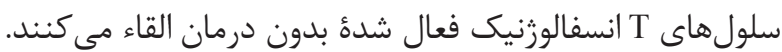

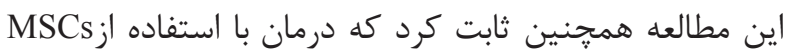

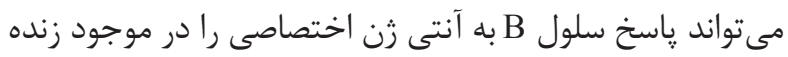

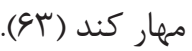

Rafei

${ }^{41}$ Chemokine (C-C motif) receptor 2 (CCR2)

${ }^{42}$ B7 Homolog 1(B7-H1)

${ }^{43}$ Syngeneic

${ }^{44}$ Neuroprotective 
همكارانش تأييد شده است ( • (9). اين مطالعه ثابت مى كند كه محيط رشد حاصل از MSC هاى انسانى مى تواند

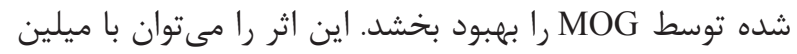

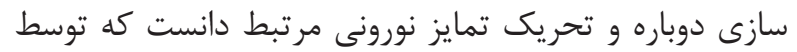
HGF

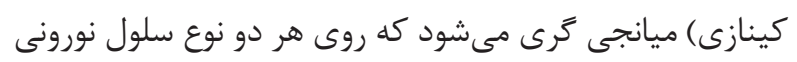

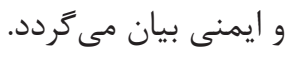

مطالعات اخير روى امكان افزايش اثر محافظت عصبى MSC ها

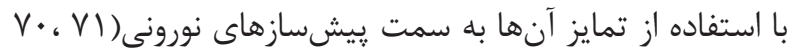

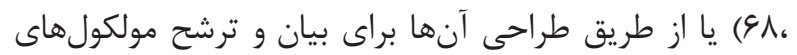

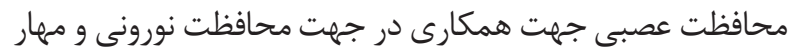

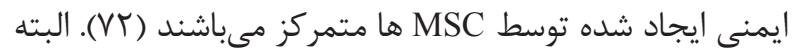

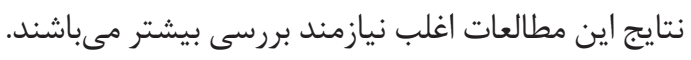
به طور كلى مطالعات يیش بالينى در خصوص نقش MSC ها Mا در

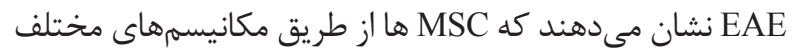

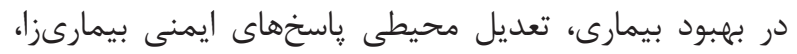

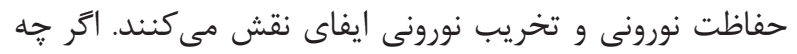

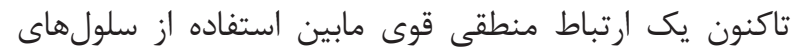

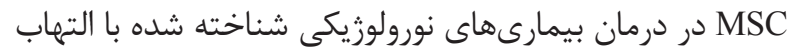

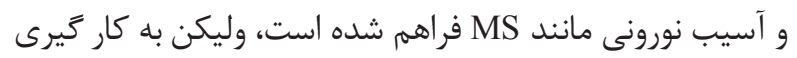

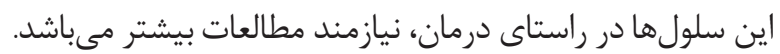

1. Bartosik-Psujek H, Stelmasiak Z. Multiple sclerosisdifficult answers to easy questions. Neurol Neurochir Pol. 2006; 40(5): 441-5.

2. Razeghi Jahromi S, Arrefhosseini SR, Ghaemi A, Alizadeh A, Moradi Tabriz H, Togha M. Alleviation of experimental allergic encephalomyelitis in C57BL/6 mice by soy daidzein. Iran J Allergy Asthma Immunol. 2014; 13(4): 256-64.

3. Kieseier BC, Hemmer B, Hartung HP. Multiple sclerosis-novel insights and new therapeutic strategies. Curr Opin Neurol. 2005; 18(3): 211-20.

4. Dong YX, Xu ZR, Lin PY. Association among serous and cerebrospinal fluid TNF-alpha level, gene polymorphisms of TNF-alpha and multiple sclerosis in Han nationality of southern China. Zhonghua Yi Xue Yi Chuan Xue Za Zhi. 2006; 23(6): 677-9.

5. Bradley WG. Neurology in clinical practice: principles of diagnosis and management. New York: Taylor \& Francis. 2004.

6. Razeghi Jahromi S, Arrefhosseini SR, Ghaemi A, Alizadeh A, Moradi Tabriz H, Togha M. Alleviation of experimental allergic encephalomyelitis in C57BL/6 mice by soy daidzein. Iran J Allergy Asthma Immunol. 2014; 13(4): 256-64.
مشابهى را در هر دو مدل EAE مزمن و نوع عود كننده فروكش

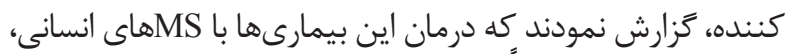

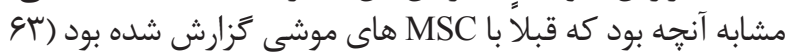

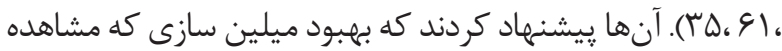

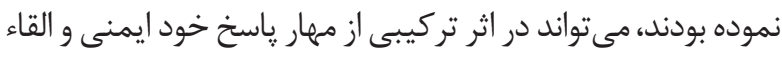

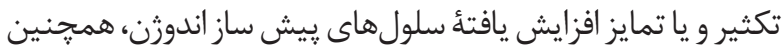

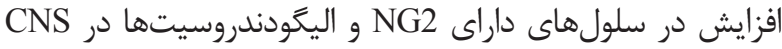
حيوانات تحت درمان باشد (1) (9).

در يك مطالعهُ مشابه كه توسط Constantin و همكارانش انجام

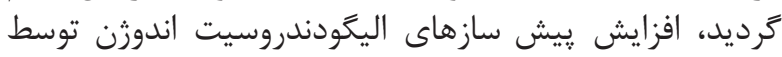
هSC

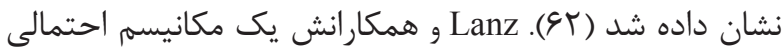

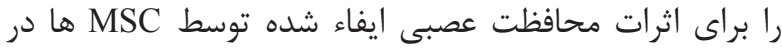
EAE

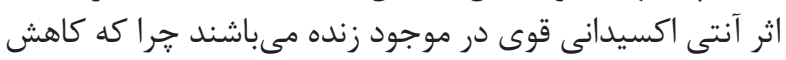

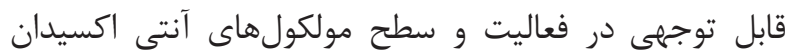
درگير در دفاع عليه آسيب بافتى و استرس اكسيداتيو القاء شده توسط EAE مشاهده گرديد (SV)

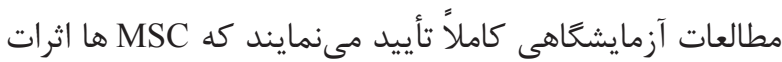

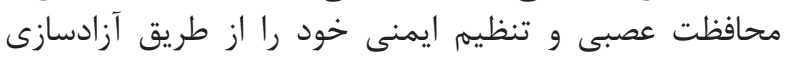

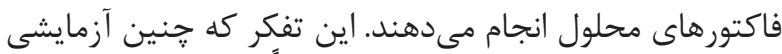
مىتواند در موجود زنده انجام شود اخيراً توسط مطالعة مai

منابع

7. Franklin RJ, Ffrench-Constant C. Remyelination in the CNS: from biology to therapy. Nat Rev Neurosci. 2008; 9(11): 839-55.

8. Aharonowiz M, Einstein O, Fainstein N, Lassmann H, Reubinoff B, Ben-Hur T. Neuroprotective effect of transplanted human embryonic stem cell-derived neural precursors in an animal model of multiple sclerosis. PloS One. 2008; 3(9): e3145. doi: 10.1371/journal. pone. 0003145 .

9. Ben-Hur T, Idelson M, Khaner H, Pera M, Reinhartz E, Itzik A, et al. Transplantation of human embryonic stem cell-derived neural progenitors improves behavioral deficit in Parkinsonian rats. Stem Cells. 2004; 22(7): 1246-55.

10. Joannides AJ, Chandran S. Human embryonic stem cells: an experimental and therapeutic resource for neurological disease. J Neurol Sci. 2008; 265(1-2): 84-8

11. Abematsu M, Tsujimura K, Yamano M, Saito M, Kohno K, Kohyama J, et al. Neurons derived from transplanted neural stem cells restore disrupted neuronal circuitry in a mouse model of spinal cord injury. J Clin Invest. 2010; 120(9): 3255-66.

12. Bacigaluppi M, Pluchino S, Peruzzotti-Jametti L, Kilic E, Kilic U, Salani G, et al. Delayed post-ischaemic 
neuroprotection following systemic neural stem cell transplantation involves multiple mechanisms. Brain. 2009; 132(Pt 8): 2239-51.

13. Pluchino S, Quattrini A, Brambilla E, Gritti A, Salani $\mathrm{G}$, Dina $\mathrm{G}$, et al. Injection of adult neurospheres induces recovery in a chronic model of multiple sclerosis. Nature. 2003; 422(6933): 688-94.

14. Pluchino S, Gritti A, Blezer E, Amadio S, Brambilla E, Borsellino G, et al. Human neural stem cells ameliorate autoimmune encephalomyelitis in non-human primates. Ann Neurol. 2009; 66(3): 343-54.

15. Czepiel M, Balasubramaniyan V, Schaafsma W, Stancic M, Mikkers H ,Huisman C, et al. Differentiation of induced pluripotent stem cells into functional oligodendrocytes. Glia. 2011; 59(6): 882-92.

16. Lebonvallet N, Boulais N, Le Gall C, Cheret J, Pereira U, Mignen O, et al. Characterization of neurons from adult human skin-derived precursors in serum-free medium : a PCR array and immunocytological analysis. Exp Dermatol. 2012; 21(3): 195-200.

17. Saporta MA, Grskovic M, Dimos JT. Induced pluripotent stem cells in the study of neurological diseases. Stem Cell Res Ther. 2011; 2(5): 37.

18. Song B, Sun G, Herszfeld D, Sylvain A, Campanale NV, Hirst CE, et al. Neural differentiation of patient specific iPS cells as a novel approach to study the pathophysiology of multiple sclerosis. Stem Cell Res. 2012; 8(2): 259-73.

19. Mancardi G, Saccardi R. Autologous haematopoietic stem-cell transplantation in multiple sclerosis. Lancet Neurol. 2008; 7(7): 626-36.

20. Muraro PA, Douek DC, Packer A, Chung K, Guenaga FJ, Cassiani-Ingoni R, et al. Thymic output generates a new and diverse TCR repertoire after autologous stem cell transplantation in multiple sclerosis patients. J Exp Med. 2005; 201(5): 805-16.

21. Uccelli A, Laroni A, Freedman MS. Mesenchymal stem cells for the treatment of multiple sclerosis and other neurological diseases. Lancet Neurol. 2011; 10(7): 649-56.

22. Gordon D, Pavlovska G, Glover CP, Uney JB, Wraith D, Scolding NJ. Human mesenchymal stem cells abrogate experimental allergic encephalomyelitis after intraperitoneal injection, and with sparse CNS infiltration. Neurosci Lett. 2008; 448(1): 71-3.

23. Le Blanc K, Frassoni F, Ball L, Locatelli F, Roelofs $\mathrm{H}$, Lewis I, et al. Mesenchymal stem cells for treatment of steroid-resistant, severe, acute graft-versus-host disease: a phase II study. Lancet. 2008; 371(9624): 1579-86.
24. Eliopoulos N, Stagg J, Lejeune L, Pommey S, Galipeau J. Allogeneic marrow stromal cells are immune rejected by MHC class I- and class II-mismatched recipient mice. Blood. 2005; 106(13): 4057-65.

25. Bartholomew A, Sturgeon C, Siatskas M, Ferrer $\mathrm{K}$, McIntosh K, Patil S, et al. Mesenchymal stem cells suppress lymphocyte proliferation in vitro and prolong skin graft survival in vivo. Exp Hematol. 2002; 30(1): 42-8.

26. Di Nicola M, Carlo-Stella C, Magni M, Milanesi M, Longoni PD, Matteucci P, et al. Human bone marrow stromal cells suppress T-lymphocyte proliferation induced by cellular or nonspecific mitogenic stimuli. Blood. 2002; 99(10): 3838-43.

27. Uccelli A ,Moretta L, Pistoia V. Mesenchymal stem cells in health and disease. Nat Rev Immunol. 2008; 8(9): 726-36.

28. Aggarwal S, Pittenger MF. Human mesenchymal stem cells modulate allogeneic immune cell responses. Blood. 2005; 105(4): 1815-22.

29. Benvenuto F, Ferrari S, Gerdoni E, Gualandi F, Frassoni F, Pistoia V, et al. Human mesenchymal stem cells promote survival of $\mathrm{T}$ cells in a quiescent state. Stem Cells. 2007; 25(7): 1753-60.

30. Chabannes D, Hill M, Merieau E, Rossignol J, Brion $\mathrm{R}$, Soulillou JP, et al. A role for heme oxygenase-1 in the immunosuppressive effect of adult rat and human mesenchymal stem cells. Blood. 2007; 110(10): 3691-4.

31. Krampera M, Glennie S, Dyson J, Scott D, Laylor R, Simpson E, et al. Bone marrow mesenchymal stem cells inhibit the response of naive and memory antigenspecific T cells to their cognate peptide. Blood. 2003; 101(9): 3722-9.

32. Meisel R, Zibert A, Laryea M, Gobel U, Daubener W, Dilloo D. Human bone marrow stromal cells inhibit allogeneic T-cell responses by indoleamine 2,3-dioxygenase-mediated tryptophan degradation. Blood. 2004; 103(12): 4619-21.

33. Sato K, Ozaki K, Oh I, Meguro A, Hatanaka K, Nagai $\mathrm{T}$, et al. Nitric oxide plays a critical role in suppression of T-cell proliferation by mesenchymal stem cells. Blood. 2007; 109(1): 228-34.

34. Tse WT, Pendleton JD, Beyer WM, Egalka MC, Guinan EC. Suppression of allogeneic T-cell proliferation by human marrow stromal cells: implications in transplantation. Transplantation. 2003; 75(3): 389-97.

35. Zappia E, Casazza S, Pedemonte E, Benvenuto F, Bonanni I, Gerdoni E, et al. Mesenchymal stem cells ameliorate experimental autoimmune encephalomyelitis inducing T-cell anergy. Blood. 2005; 106(5): 1755-61. 
36. Glennie S, Soeiro I, Dyson PJ, Lam EW ,Dazzi F. Bone marrow mesenchymal stem cells induce division arrest anergy of activated T cells. Blood. 2005; 105(7): 2821-7.

37. Selmani Z, Naji A, Zidi I, Favier B, Gaiffe E, Obert $\mathrm{L}$, et al. Human leukocyte antigen-G5 secretion by human mesenchymal stem cells is required to suppress $\mathrm{T}$ lymphocyte and natural killer function and to induce $\mathrm{CD}^{4+} \mathrm{CD} 25$ high $\mathrm{FOXP}^{3+}$ regulatory T cells. Stem Cells. 2008; 26(1): 212-22.

38. Krampera M, Cosmi L, Angeli R, Pasini A, Liotta $\mathrm{F}$, Andreini A, et al. Role for interferon-gamma in the immunomodulatory activity of human bone marrow mesenchymal stem cells. Stem Cells. 2006;24(2):386-98.

39. Maccario R, Podesta M, Moretta A, Cometa A, Comoli P, Montagna D, et al. Interaction of human mesenchymal stem cells with cells involved in alloantigen-specific immune response favors the differentiation of $\mathrm{CD}^{4+}$ T-cell subsets expressing a regulatory/suppressive phenotype. Haematologica. 2005; 90(4): 516-25.

40. Pevsner-Fischer M, Morad V, Cohen-Sfady M, Rousso-Noori L, Zanin-Zhorov A, Cohen S, et al. Tolllike receptors and their ligands control mesenchymal stem cell functions. Blood. 2007; 109(4): 1422-32.

41. Tomchuck SL, Zwezdaryk KJ, Coffelt SB, Waterman RS, Danka ES, Scandurro AB. Toll-like receptors on human mesenchymal stem cells drive their migration and immunomodulating responses. Stem Cells. 2008; 26(1): 99-107.

42. Liotta F, Angeli R, Cosmi L, Fili L, Manuelli C, Frosali F, et al. Toll-like receptors 3 and 4 are expressed by human bone marrow-derived mesenchymal stem cells and can inhibit their T-cell modulatory activity by impairing Notch signaling. Stem Cells. 2008; 26(1): 279-89.

43. Svensson M, Kaye PM. Stromal-cell regulation of dendritic-cell differentiation and function. Trends Immunol. 2006; 27(12): 580-7.

44. Augello A, Tasso R, Negrini SM, Amateis A, Indiveri $\mathrm{F}$, Cancedda R, et al. Bone marrow mesenchymal progenitor cells inhibit lymphocyte proliferation by activation of the programmed death 1 pathway. Eur J Immunol. 2005; 35(5): 1482-90.

45. Corcione A, Benvenuto F, Ferretti E, Giunti D, Cappiello V, Cazzanti F, et al. Human mesenchymal stem cells modulate B-cell functions. Blood. 2006; 107(1): 367-72.

46. Rasmusson I, Le Blanc K, Sundberg B, Ringden O. Mesenchymal stem cells stimulate antibody secretion in human B cells. Scand J Immunol. 2007; 65(4): 336-43.

47. Traggiai E, Volpi S, Schena F, Gattorno M, Ferlito F, Moretta L, et al. Bone marrow-derived mesenchymal stem cells induce both polyclonal expansion and differentiation of B cells isolated from healthy donors and systemic lupus erythematosus patients. Stem Cells. 2008; 26(2): 562-9.

48. Djouad F, Charbonnier LM, Bouffi C, Louis-Plence $\mathrm{P}$, Bony $\mathrm{C}$,Apparailly $\mathrm{F}$, et al. Mesenchymal stem cells inhibit the differentiation of dendritic cells through an interleukin-6-dependent mechanism. Stem Cells. 2007; 25(8): 2025-32.

49. Jiang XX, Zhang Y, Liu B, Zhang SX, Wu Y, Yu $\mathrm{XD}$, et al. Human mesenchymal stem cells inhibit differentiation and function of monocyte-derived dendritic cells. Blood. 2005; 105(10): 4120-6.

50. Nauta AJ, Kruisselbrink AB, Lurvink E, Willemze R, Fibbe WE. Mesenchymal stem cells inhibit generation and function of both $\mathrm{CD}^{34+}$-derived and monocytederived dendritic cells. J Immunol. 2006; 177(4): 2080-7.

51. Chiesa S, Morbelli S, Morando S, Massollo M, Marini C, Bertoni A, et al. Mesenchymal stem cells impair in vivo T-cell priming by dendritic cells. Proc Natl Acad Sci U S A. 2011; 108(42): 17384-9.

52. Zhou C, Zhang C, Chi S, Xu Y, Teng J, Wang H, et al. Effects of human marrow stromal cells on activation of microglial cells and production of inflammatory factors induced by lipopolysaccharide. Brain Res. 2009; 1269: 23-30.

53. Spaggiari GM, Capobianco A, Becchetti S, Mingari MC, Moretta L. Mesenchymal stem cell-natural killer cell interactions: evidence that activated NK cells are capable of killing MSCs, whereas MSCs can inhibit IL-2-induced NK-cell proliferation. Blood. 2006; 107(4): 1484-90.

54. Spaggiari GM, Capobianco A, Abdelrazik H, Becchetti F, Mingari MC, Moretta L. Mesenchymal stem cells inhibit natural killer-cell proliferation, cytotoxicity, and cytokine production: role of indoleamine 2,3-dioxygenase and prostaglandin E2. Blood. 2008; 111(3): 1327-33.

55. Poggi A, Prevosto C, Massaro AM, Negrini S, Urbani S, Pierri I, et al. Interaction between human NK cells and bone marrow stromal cells induces NK cell triggering: role of NKp30 and NKG2D receptors. J Immunol. 2005; 175(10): 6352-60.

56. Lünemann JD1, Münz C. Do natural killer cells accelerate or prevent autoimmunity in multiple sclerosis? Brain. 2008; 131(Pt 7): 1681-3.

57. Wright HL, Moots RJ, Bucknall RC, Edwards SW. 


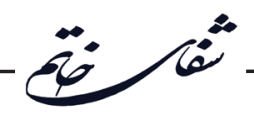

Neutrophil function in inflammation and inflammatory diseases. Rheumatology (Oxford). 2010; 49(9): 1618-31.

58. Naegele M, Tillack K, Reinhardt S, Schippling S, Martin R, Sospedra M. Neutrophils in multiple sclerosis are characterized by a primed phenotype. $\mathrm{J}$ Neuroimmunol. 2012; 242(1-2): 60-71.

59. Raffaghello L, Bianchi G, Bertolotto M, Montecucco F, Busca A, Dallegri F, et al. Human mesenchymal stem cells inhibit neutrophil apoptosis: a model for neutrophil preservation in the bone marrow niche. Stem Cells. 2008; 26(1): 151-62.

60. Bai L, Lennon DP, Caplan AI, DeChant A, Hecker J, Kranso J, et al. Hepatocyte growth factor mediates mesenchymal stem cell-induced recovery in multiple sclerosis models. Nat Neurosci. 2012; 15(6): 862-70.

61. Bai L, Lennon DP, Eaton V, Maier K, CaplanAI, Miller $\mathrm{SD}$, et al. Human bone marrow-derived mesenchymal stem cells induce Th2-polarized immune response and promote endogenous repair in animal models of multiple sclerosis. Glia. 2009; 57(11): 1192-203.

62. Constantin G, Marconi S, Rossi B, Angiari S, Calderan L, Anghileri E, et al. Adipose-derived mesenchymal stem cells ameliorate chronic experimental autoimmune encephalomyelitis. Stem Cells. 2009; 27(10): 2624-35.

63. Gerdoni E, Gallo B, Casazza S, Musio S, Bonanni I, Pedemonte E, et al. Mesenchymal stem cells effectively modulate pathogenic immune response in experimental autoimmune encephalomyelitis. Ann Neurol. 2007; 61(3): 219-27.

64. Rafei M, Campeau PM, Aguilar-Mahecha A, Buchanan M, Williams P, Birman E, et al. Mesenchymal stromal cells ameliorate experimental autoimmune encephalomyelitis by inhibiting CD4 Th17 T cells in a $\mathrm{CC}$ chemokine ligand 2-dependent manner. J Immunol. 2009; 182(10): 5994-6002.

65. Zhang J, Li Y, Lu M, Cui Y, Chen J, Noffsinger L, et al. Bone marrow stromal cells reduce axonal loss in experimental autoimmune encephalomyelitis mice. J Neurosci Res. 2006; 84(3): 587-95.

66. Kassis I, Grigoriadis N, Gowda-Kurkalli B, MizrachiKol R, Ben-Hur T, Slavin S, et al. Neuroprotection and immunomodulation with mesenchymal stem cells in chronic experimental autoimmune encephalomyelitis. Arch Neurol. 2008; 65(6): 753-61.

67. Lanz TV, Opitz CA, Ho PP, Agrawal A, Lutz C, Weller M, et al. Mouse mesenchymal stem cells suppress antigen-specific TH cell immunity independent of indoleamine 2,3-dioxygenase 1 (IDO1). Stem Cells Dev. 2010; 19(5): 657-68.

68. Matysiak M, Stasiolek M, Orlowski W, Jurewicz A, Janczar S, Raine CS, et al. Stem cells ameliorate EAE via an indoleamine 2,3-dioxygenase (IDO) mechanism. J Neuroimmunol. 2008; 193(1-2): 12-23.

69. Gordon D, Pavlovska G, Uney JB, Wraith DC, Scolding NJ. Human mesenchymal stem cells infiltrate the spinal cord, reduce demyelination, and localize to white matter lesions in experimental autoimmune encephalomyelitis. J Neuropathol Exp Neurol. 2010; 69(11): 1087-95.

70. Harris VK, Yan QJ, Vyshkina T, Sahabi S, Liu $\mathrm{X}$, Sadiq SA. Clinical and pathological effects of intrathecal injection of mesenchymal stem cell-derived neural progenitors in an experimental model of multiple sclerosis. J Neurol Sci. 2012; 313(1-2): 167-77.

71. Matysiak M, Orlowski W, Fortak-Michalska M, Jurewicz A, Selmaj K. Immunoregulatory function of bone marrow mesenchymal stem cells in EAE depends on their differentiation state and secretion of PGE2. J Neuroimmunol. 2011; 233(1-2): 106-11.

72. Lu Z, Hu X, Zhu C, Wang D, Zheng X, Liu Q. Overexpression of CNTF in Mesenchymal Stem Cells reduces demyelination and induces clinical recovery in experimental autoimmune encephalomyelitis mice. J Neuroimmunol. 2009; 206(1-2): 58-69. 